\title{
BIOSORPTION OF TEXTILE INDUSTRY EFFLUENT USING ACID TREATED SUGARCANE BAGASSE: FACTORIAL DESIGN OF EXPERIMENTS
}

\author{
Mahalakshmi Mathivanan* and Saranaathan S.E \\ School of Civil Engineering, SASTRA University, Thanjavur, Tamilnadu, India \\ *E-mail : mahalakshmi@ civil.sastra.edu
}

\begin{abstract}
The purpose of the study is to investigate the decolorization of textile dye effluent (maximum wavelength $=540 \mathrm{~nm}$ ) with acid treated sugarcane bagasse using the factorial design of experiments. Two level of process variables namely dilution percentage (10 and 50\%), adsorbent dosage (2 and $8 \mathrm{mg} / \mathrm{dm}^{3}$ ), initial $\mathrm{pH}(2$ and 8$)$ and agitation speed (50 and $200 \mathrm{rpm}$ ) were considered in the factorial design of experiments. The regression coefficients, student t-test, residual plot were performed in order to examine the fitness of experimental data. Finally, the interaction among the process variables and main effects on \% color removal and \% COD removal were determined.
\end{abstract}

Keywords: Sugarcane bagasse, Factorial design, Decolourization, Textile effluent

(C) RASĀYAN. All rights reserved

\section{INTRODUCTION}

Dyes are colored substances that expose in the range between 400 and $700 \mathrm{~nm}$. Textile and dyeing industries used different types of dye stuff. The selection of dye stuff depends upon the dyeing process, nature of fiber used and economical aspects. According to the ionic dispersion, industrial dyes are classified as follows:

(i) Non-ionic (direct dyes);

(ii) Anionic (reactive, acid and direct dyes);

(iii) Cationic (base dyes) ${ }^{1}$.

It is reported that more than $7 \times 10^{5}$ Metric tonnes of dye are used in various dyeing and textile industry per year. A hetero-cylic aromatic chemical compound in the dye is widely used in paper\& pulp, acrylic, silk, wool, and bleaching industries due to a high degree of dispersion. These types of dyes are highly biodegradable due to the presence of the aromatic structure.

Owing to toxic nature, chemical composition and volume discharged, the dye effluent disposed of various textile and dyeing industries can be considered as pollutants in Asian countries ${ }^{2}$ and it must be treated by appropriate technique in order to save surroundings ${ }^{3}$. The effluent discharged from textile and dyeing industry contains toxic, mutagenic, carcinogenic chemical compounds which are harmful to live organisms and human being ${ }^{4}$.

The dye effluent can be treated by physical, chemical and microbiological methods. However, microbiological methods have certain limitations like longer treatment time and less color removal. Several researchers have focused on physical and chemical methods namely adsorption, electrochemical, coagulation, membrane filtration, ion-exchange and oxidation for the removal of color from textile effluent.

Adsorption technique is a cost-effective method for the removal of pollutant from textile waste water due to the usage of low-cost adsorbent ${ }^{5}$.

The commonly used for the decolorization of textile effluent are activated carbon ${ }^{6}$, peat ${ }^{7}$, wood chips, coal and fly ash mixture ${ }^{8}$. Natural materials and industrial solid wastes namely agriculture wastes such as rice husk ${ }^{9}$, wheat shell $^{10}$, fly ash $^{11}$, modified rice straw chemically treated \& untreated guava leaves ${ }^{12}$, groundnut shell powder, carbon nano-tubes ${ }^{13}$, carbonized plant leaf ${ }^{14}$, silk tree or oil cake tree leaf biomass ${ }^{15}$ can be employed as potential adsorbent for decolorization of dye effluent. In agricultural 
countries like India, there is an abundant availability of residue which becomes more attractive for removal of pollutants from textile industry waste water. Sugarcane bagasse has been used as an alternative adsorbent for the removal of colour as it is cheap and abundantly available in India. It illustrates good adsorption capability after acid treatment ${ }^{5}$.

In order to identify the interaction effects and main effects on response variable with a minimum number of trials, the two-level factorial design was employed. Therefore, it is more efficient than conventional experiments with one variable at a time ${ }^{5}$. The percentage dilution, adsorbent dosage, initial $\mathrm{pH}$ and agitation speed are essential to processing variables during adsorption. Thus in the present study, batch adsorption was performed in order to remove the color as well as COD by changing factors at two levels. Interaction among the process variables and main effect were studied.

\section{EXPERIMENTAL}

The stock solution was prepared according to the design of experiments (Table-2.) by adding a suitable volume of distilled water. The four variables namely dilution rate, adsorbent dosage, initial $\mathrm{pH}$ and agitation speed were changed at two levels in the design of experiments. For each trial, $100 \mathrm{ml}$ of stock industrial effluent was taken in which necessary medium/process variables were considered according to the design of experiments. The sample was kept in a rotary shaker for $2 \mathrm{hrs}$. The sample was filtered and absorbance was determined by UV-vis spectrophotometer (Systronics). Totally sixteen experiments were carried out with replicates at $303 \mathrm{~K}$.

\section{Statistical Analysis}

In the factorial design of the experiment, a statistical model is used to understand the interaction among the process variables involved in adsorption of dye effluent on treated sugarcane bagasse on response variable by performing a limited number of experiments. The general full factorial design was employed for the decolorization of dye effluent with three independent variables namely dilution rate (A), the dosage of adsorbent (B), initial $\mathrm{pH}(\mathrm{C})$ and agitation speed (D). The following quadratic equation is used to explain the behavior of the system ${ }^{5,16}$.

$$
\begin{aligned}
& Y=a_{o}+a_{1} x_{1}+a_{2} x_{2}+a_{3} x_{3}+a_{4} x_{4}+a_{5}\left(x_{1} \times x_{2}\right)+a_{6}\left(x_{1} \times x_{3}\right)+a_{7}\left(x_{1} \times x_{4}\right)+a_{8}\left(x_{2} \times x_{3}\right) \\
& +a_{9}\left(x_{2} \times x_{4}\right)+a_{10}\left(x_{3} \times x_{4}\right)+a_{11}\left(x_{1} \times x_{2} \times x_{3}\right)+a_{12}\left(x_{1} \times x_{2} \times x_{4}\right)+a_{13}\left(x_{1} \times x_{3} \times x_{4}\right)+ \\
& a_{14}\left(x_{2} \times x_{3} \times x_{4}\right)+a_{13}\left(x_{1} \times x_{2} \times x_{3} \times x_{4}\right)
\end{aligned}
$$

Student t-test and ANOVA were performed by regression analysis using Minitabe (Version 16) statistical software. In regression analysis, the variables with which more student t-test value and low probability value $(\mathrm{P}<0.05$ with $95 \%$ level of significance) were statistically significant. ANOVA explains the interaction among the variables on the response variable. The level of variables chosen was listed in Table-1. The percentage removal of dye and percentage removal of COD were determined as:

$$
\begin{aligned}
& \text { \%color removal }=\left(\frac{O D_{\text {initial }}-O D_{\text {final }}}{O D_{\text {initial }}}\right) \\
& \% C O D \text { removal }=\left(\frac{C O D_{\text {initial }}-C O D_{\text {final }}}{C O D_{\text {initial }}}\right)
\end{aligned}
$$

Table-1: Levels of factors for the treatment of dye effluent

\begin{tabular}{c|c|c}
\hline Variables & Low & High \\
\hline Dilution (A), $\%$ & 10 & 50 \\
\hline Adsorbent dosage (B), $\mathrm{mg} / \mathrm{dm}^{3}$ & 2 & 8 \\
\hline Initial pH (C) & 2 & 8 \\
\hline Agitation speed (D), rpm & 50 & 200 \\
\hline
\end{tabular}




\section{RESULTS AND DISCUSSION}

Experimental results are listed in Table-2. Using Minitab (Version 16) statistical software, the interaction among the variables and main effects on response variables were examined. The effect of a factor is the variation in response variable (percentage color removal/percentage COD removal) with respect to change in independent variables namely dilution rate, adsorbent dosage, initial $\mathrm{pH}$ and agitation speed from a low level to high level.

Regression was performed and model coefficients were listed in Table-3.In the regression analysis, the main effect indicates the deviation of the mean from lower to a high value for each one of them ${ }^{5}$. The positive main effect indicates the positive change in response variable from the lower level to higher level. However, the negative value of the main effect describes the decrease in response variable from low to high level ${ }^{5}$. The effect of a factor is the variation of response variables, percentage decolorization and percentage COD removal due to change in the level of variables namely dilution factor, adsorbent dosage, initial $\mathrm{pH}$ and agitation speed from lower level to higher level.

Table-2: Design of experiments for color and COD removal

\begin{tabular}{|c|c|c|c|c|c|c|c|c|}
\hline \multirow{2}{*}{$\begin{array}{l}\text { Run } \\
\text { Order }\end{array}$} & \multirow[b]{2}{*}{ A } & \multirow[b]{2}{*}{ B } & \multirow[b]{2}{*}{ C } & \multirow[b]{2}{*}{ D } & \multicolumn{2}{|c|}{$\begin{array}{c}\% \text { Colour } \\
\text { removal }\end{array}$} & \multicolumn{2}{|c|}{$\begin{array}{l}\% \text { COD } \\
\text { removal }\end{array}$} \\
\hline & & & & & Run 1 & Run 2 & Run 1 & Run 2 \\
\hline 1 & 10 & 2 & 2 & 50 & 25.43 & 34.5 & 6.2 & 10.24 \\
\hline 2 & 10 & 2 & 2 & 200 & 42.57 & 47.97 & 14.54 & 18.4 \\
\hline 3 & 10 & 2 & 8 & 50 & 38.79 & 36.67 & 17.89 & 21.12 \\
\hline 4 & 10 & 2 & 8 & 200 & 45.34 & 43.67 & 24.12 & 27.4 \\
\hline 5 & 10 & 8 & 2 & 50 & 33.56 & 36.81 & 21.45 & 18.57 \\
\hline 6 & 10 & 8 & 2 & 200 & 52.45 & 46.87 & 27.65 & 32.14 \\
\hline 7 & 10 & 8 & 8 & 50 & 64.32 & 56.34 & 49.87 & 45.54 \\
\hline 8 & 10 & 8 & 8 & 200 & 79.56 & 76.78 & 72.34 & 64.94 \\
\hline 9 & 50 & 2 & 2 & 50 & 21.12 & 17.12 & 4.5 & 5.4 \\
\hline 10 & 50 & 2 & 2 & 200 & 33.24 & 27.67 & 13.54 & 12.9 \\
\hline 11 & 50 & 2 & 8 & 50 & 28.78 & 32.14 & 8.56 & 12.29 \\
\hline 12 & 50 & 2 & 8 & 200 & 39.56 & 42.34 & 14.23 & 16.54 \\
\hline 13 & 50 & 8 & 2 & 50 & 27.89 & 24.7 & 10.78 & 12.34 \\
\hline 14 & 50 & 8 & 2 & 200 & 40.97 & 35.98 & 12.65 & 15.98 \\
\hline 15 & 50 & 8 & 8 & 50 & 46.57 & 42.32 & 35.67 & 42.34 \\
\hline 16 & 50 & 8 & 8 & 200 & 58.97 & 54.64 & 49.8 & 46.87 \\
\hline
\end{tabular}

The percentage colour removal efficiency $\left(\mathrm{Y}_{1}\right)$ and percentage COD removal efficiency $\left(\mathrm{Y}_{2}\right)$ were determined by the following regression equation in terms of coded variables:

$Y_{1}=41.74+5.86 A-6.93 B-7.44 C-6.3 D-1.3(A \times B)-0.15(A \times C)-0.5(A \times D)+3.83(B \times C)$

$+0.81(B \times D)-0.36(C \times D)+2(A \times B \times C)+0.47(A \times B \times D)-0.28(A \times C \times D)-0.81(B \times C \times D)$

$-0.68(A \times B \times C \times D)$

$Y_{2}=24.59+4.94 A-10.35 B-9.76 C-4.42 D-1.69(A \times B)-1.12(A \times C)-1.25(A \times D)$

$+6.23(B \times C)+0.95(B \times D)+0.77(C \times D)-0.5(A \times B \times C)+1.09(A \times B \times D)+0.36(B \times C \times D)$

$-1.43(A \times C \times D)-0.2(A \times B \times C \times D)$ 
RASĀYAN J. Chem.

Vol. 11 | No. 2 |877 - 885 | April - June | 2018

Table-3: Regression coefficients for \% colour removal and \% COD removal

\begin{tabular}{|c|c|c|c|c|c|c|c|c|}
\hline & \multicolumn{4}{|c|}{$\%$ Colour removal } & \multicolumn{4}{|c|}{$\%$ COD removal } \\
\hline Term & Coeff & $\begin{array}{c}\text { SE } \\
\text { Coef }\end{array}$ & $\mathrm{T}$ & $\mathrm{P}$ & Coeff & $\begin{array}{c}\mathrm{SE} \\
\text { coef }\end{array}$ & $\mathrm{T}$ & $\mathrm{P}$ \\
\hline Constant & 41.74 & 0.6 & 69.46 & 0 & 24.59 & 0.49 & 50.64 & 0 \\
\hline A & 5.86 & 0.6 & 9.76 & 0 & 4.94 & 0.49 & 10.17 & 0 \\
\hline B & -6.93 & 0.6 & -11.54 & 0 & -10.35 & 0.49 & -21.31 & 0 \\
\hline $\mathrm{C}$ & -7.44 & 0.6 & -12.37 & 0 & -9.76 & 0.49 & -20.09 & 0 \\
\hline $\mathrm{D}$ & -6.3 & 0.6 & -10.48 & 0 & -4.42 & 0.49 & -9.09 & 0 \\
\hline $\mathrm{A} \times \mathrm{B}$ & -1.3 & 0.6 & -2.17 & 0.04 & -1.69 & 0.49 & -3.48 & 0 \\
\hline $\mathrm{A} \times \mathrm{C}$ & -0.15 & 0.6 & -0.24 & 0.81 & -1.12 & 0.49 & -2.31 & 0.04 \\
\hline$A \times D$ & -0.50 & 0.6 & -0.84 & 0.41 & -1.25 & 0.49 & -2.58 & 0.02 \\
\hline $\mathrm{B} \times \mathrm{C}$ & 3.83 & 0.6 & 6.38 & 0 & 6.23 & 0.49 & 12.83 & 0 \\
\hline $\mathrm{B} \times \mathrm{D}$ & 0.81 & 0.6 & 1.35 & 0.19 & 0.95 & 0.49 & 1.95 & 0.07 \\
\hline$C \times D$ & -0.37 & 0.6 & -0.6 & 0.55 & 0.77 & 0.49 & .59 & 0.13 \\
\hline $\begin{array}{c}\mathrm{A} \times \mathrm{B} \\
\times \mathrm{C}\end{array}$ & & 0.6 & 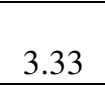 & 0 & -0.50 & 0.49 & -1.02 & 0.32 \\
\hline $\begin{array}{c}\mathrm{A} \times \mathrm{B} \\
\times \mathrm{D}\end{array}$ & & 0.6 & & 0.44 & & 0.49 & 2.25 & 0.04 \\
\hline $\begin{array}{c}\mathrm{A} \times \mathrm{C} \\
\times \mathrm{D}\end{array}$ & & 0.6 & -0 & 34 & 36 & 0.49 & .75 & 0.47 \\
\hline $\begin{array}{c}\mathrm{B} \times \mathrm{C} \\
\times \mathrm{D}\end{array}$ & -0.81 & 0.6 & -1.34 & 0.198 & -1.43 & 0.49 & -2.95 & 0 \\
\hline $\begin{array}{r}\mathrm{A} \times \mathrm{B} \\
\times \mathrm{C} \times \mathrm{D}\end{array}$ & -0.68 & 0.6 & -1.13 & 0.275 & -0.1975 & 0.49 & -0.41 & 0.69 \\
\hline $\mathrm{S}=3.3$ & $20 ; \mathrm{R}$ & $\begin{array}{l}q=97 \\
94.57 \%\end{array}$ & R-S & & $\mathrm{S}^{2}$ & $\begin{array}{l}46 ; 1 \\
5 q(a d\end{array}$ & $\begin{array}{l}=98.74 \\
97.56 \%\end{array}$ & \\
\hline
\end{tabular}

The student t-test and F-test are employed to examine the statistical significance of variables on response variables. The statistical significance of each variable involved in regression analysis was described by probability (p) value with $95 \%$ level of significance. Higher t-test value and lower p-value indicate the significance of terms involved in regression analysis. The medium/process variables were statistically significant when the p-value is lower than 0.05 with $95 \%$ level of significance in regression analysis ${ }^{5,16}$.

Fig.1 explains the main effects of percentage color removal and percentage COD removal. The percentage removal of color and COD removal were directly proportional to adsorbent dosage, initial $\mathrm{pH}$ and agitation speed. However, the mean of response variables was inversely proportional to dilution rate. The percentage of COD removal is slightly changed with respect to agitation speed.

The ratio of the mean square and mean square error was examined by ANOVA test. F-value for interaction terms (two and three-way) in the ANOVA lower than the equivalent F-value from the statistical table with $95 \%$ level of significance. ANOVA was performed for percentage removal of color and COD reduction (Table-4 (a) and (b)).

For percentage color removal, all the linear terms, two-way interaction terms namely dilution factor $\times$ dosage; dosage $\times$ initial $\mathrm{pH}$ and three-way interactions terms such as dilution factor $\times$ dosage $\times$ initial $\mathrm{pH}$ involved in the regression analysis were statistically significant due to higher F-value and lower p-value $(<0.05)$. Few interaction terms were statistically insignificant due to lower F-value and higher p-value $(>0.05)$. Therefore, these interaction terms are removed from the regression equation for the determination of percentage color removal. The reduced regression equation for percentage removal of color with significant regression coefficient is given by in terms of uncoded units:

$Y_{1}=41.74+5.86 A-6.93 B-7.44 C-6.3 D-1.3(A \times B)+3.83(B \times C)+2(A \times B \times C)$ 
RASĀYAN J. Chem.

Vol. 11 | No. 2 |877 - 885 | April - June | 2018

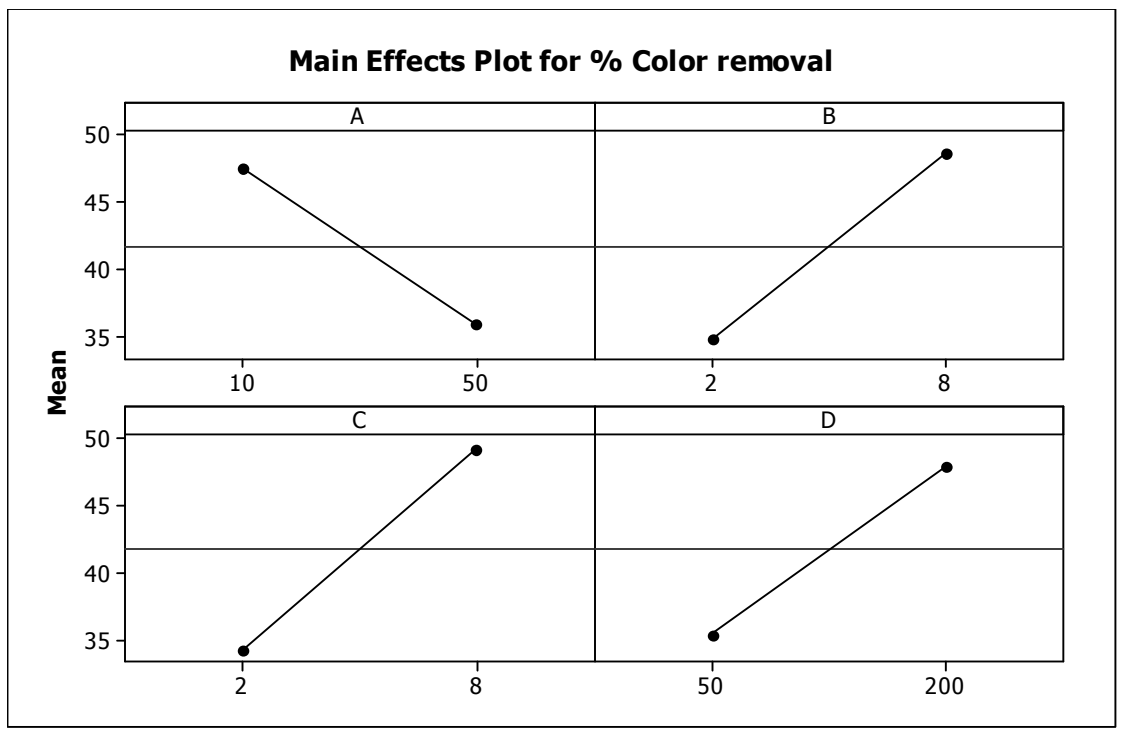

(a)

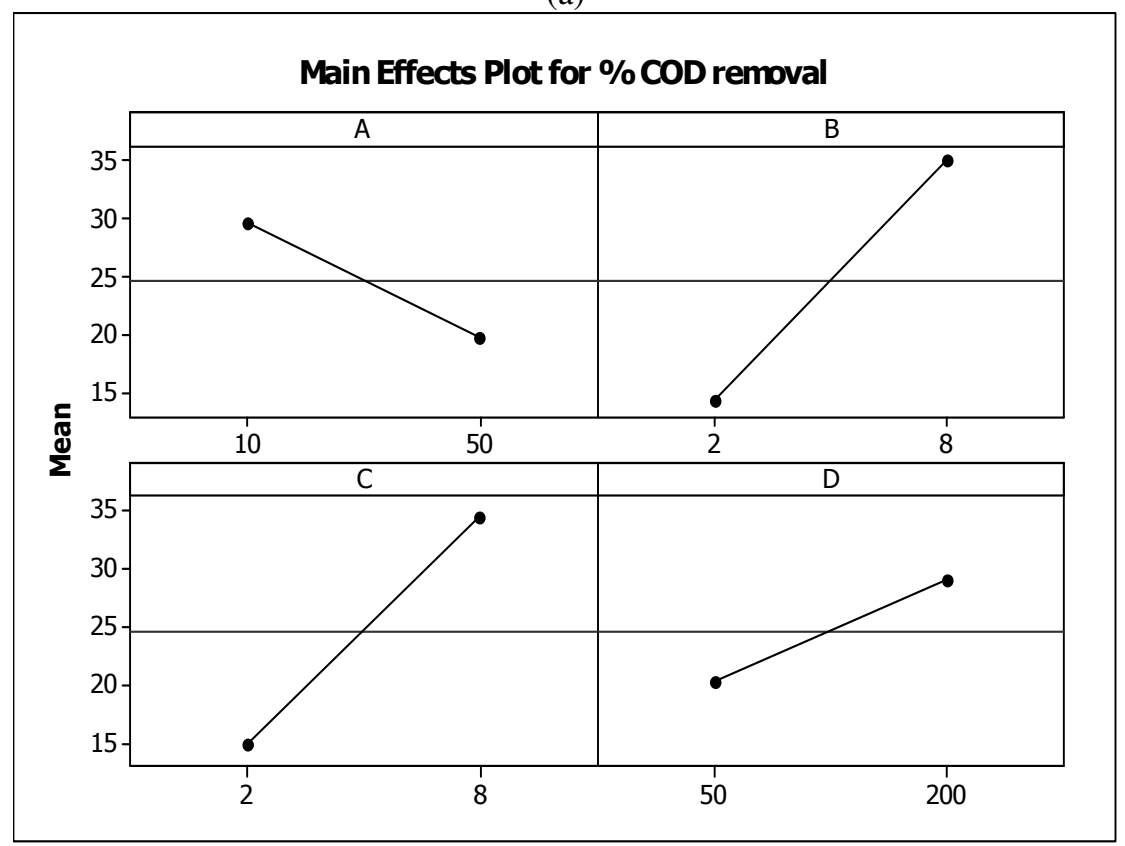

(b)

Fig.-1: Main effects plot (a) colour removal (b) COD removal

Table-4(a): AVOVA for colour removal

\begin{tabular}{l|l|l|l|l|l|l}
\hline Source & DF & Seq SS & Adj SS & Adj MS & F & P \\
\hline $\mathrm{A}$ & 1 & 1100.04 & 1100.04 & 1100.04 & 95.2 & 0 \\
\hline $\mathrm{B}$ & 1 & 1537.63 & 1537.63 & 1537.63 & 133.08 & 0 \\
\hline $\mathrm{C}$ & 1 & 1769.23 & 1769.23 & 1769.23 & 153.12 & 0 \\
\hline $\mathrm{D}$ & 1 & 1269.07 & 1269.07 & 1269.07 & 109.83 & 0 \\
\hline $\mathrm{A} \times \mathrm{B}$ & 1 & 54.29 & 54.29 & 54.29 & 4.7 & 0.046 \\
\hline $\mathrm{A} \times \mathrm{C}$ & 1 & 0.68 & 0.68 & 0.68 & 0.06 & 0.811 \\
\hline $\mathrm{A} \times \mathrm{D}$ & 1 & 8.06 & 8.06 & 8.06 & 0.7 & 0.416 \\
\hline $\mathrm{B} \times \mathrm{C}$ & 1 & 469.71 & 469.71 & 469.71 & 40.65 & 0 \\
\hline $\mathrm{B} \times \mathrm{D}$ & 1 & 20.96 & 20.96 & 20.96 & 1.81 & 0.197 \\
\hline $\mathrm{C} \times \mathrm{D}$ & 1 & 4.25 & 4.25 & 4.25 & 0.37 & 0.553 \\
\hline
\end{tabular}


RASĀYAN J. Chem.

Vol. 11 | No. 2 |877 - 885 | April - June | 2018

\begin{tabular}{l|l|l|l|l|l|l}
\hline $\mathrm{A} \times \mathrm{B} \times \mathrm{C}$ & 1 & 128.08 & 128.08 & 128.08 & 11.08 & 0.004 \\
\hline $\mathrm{A} \times \mathrm{B} \times \mathrm{D}$ & 1 & 7.07 & 7.07 & 7.07 & 0.61 & 0.446 \\
\hline $\mathrm{A} \times \mathrm{C} \times \mathrm{D}$ & 1 & 2.53 & 2.53 & 2.53 & 0.22 & 0.646 \\
\hline $\mathrm{B} \times \mathrm{C} \times \mathrm{D}$ & 1 & 20.87 & 20.87 & 20.87 & 1.81 & 0.198 \\
\hline $\mathrm{A} \times \mathrm{B} \times \mathrm{C} \times \mathrm{D}$ & 1 & 14.77 & 14.77 & 14.77 & 1.28 & 0.275 \\
\hline Error & 16 & 184.87 & 184.87 & 11.55 & & \\
\hline Total & 31 & 6592.12 & & & & \\
\hline
\end{tabular}

Table-4(b): ANOVA for COD removal

\begin{tabular}{c|c|c|c|c|c|c}
\hline Source & DF & Seq SS & Adj SS & Adj MS & F & P \\
\hline $\mathrm{A}$ & 1 & 780.32 & 780.32 & 780.32 & 103.42 & 0 \\
\hline $\mathrm{B}$ & 1 & 3425.02 & 3425.02 & 3425.02 & 453.94 & 0 \\
\hline $\mathrm{C}$ & 1 & 3046.68 & 3046.68 & 3046.68 & 403.8 & 0 \\
\hline $\mathrm{D}$ & 1 & 623.75 & 623.75 & 623.75 & 82.67 & 0 \\
\hline $\mathrm{A} \times \mathrm{B}$ & 1 & 91.53 & 91.53 & 91.53 & 12.13 & 0.003 \\
\hline $\mathrm{A} \times \mathrm{C}$ & 1 & 40.1 & 40.1 & 40.1 & 5.31 & 0.035 \\
\hline $\mathrm{A} \times \mathrm{D}$ & 1 & 50.05 & 50.05 & 50.05 & 6.63 & 0.02 \\
\hline $\mathrm{B} \times \mathrm{C}$ & 1 & 1242.26 & 1242.26 & 1242.26 & 164.65 & 0 \\
\hline $\mathrm{B} \times \mathrm{D}$ & 1 & 28.77 & 28.77 & 28.77 & 3.81 & 0.069 \\
\hline $\mathrm{C} \times \mathrm{D}$ & 1 & 18.97 & 18.97 & 18.97 & 2.51 & 0.132 \\
\hline $\mathrm{A} \times \mathrm{B} \times \mathrm{C}$ & 1 & 7.92 & 7.92 & 7.92 & 1.05 & 0.321 \\
\hline $\mathrm{A} \times \mathrm{B} \times \mathrm{D}$ & 1 & 38.11 & 38.11 & 38.11 & 5.05 & 0.039 \\
\hline $\mathrm{A} \times \mathrm{C} \times \mathrm{D}$ & 1 & 4.19 & 4.19 & 4.19 & 0.56 & 0.467 \\
\hline $\mathrm{B} \times \mathrm{C} \times \mathrm{D}$ & 1 & 65.72 & 65.72 & 65.72 & 8.71 & 0.009 \\
\hline $\mathrm{A} \times \mathrm{B} \times \mathrm{C} \times \mathrm{D}$ & 1 & 1.25 & 1.25 & 1.25 & 0.17 & 0.69 \\
\hline Error & 16 & 120.72 & 120.72 & 7.55 & & \\
\hline Total & 31 & 9585.36 & & & & \\
\hline
\end{tabular}

In the regression analysis for percentage removal of $\mathrm{COD}$, all the linear terms and interaction terms other than interaction of dosage with agitation speed $(B \times D)$, interaction of initial $\mathrm{pH}$ with agitation speed $(\mathrm{C} \times \mathrm{D})$, three-way interaction terms, $\mathrm{A} \times \mathrm{B} \times \mathrm{C}, \mathrm{A} \times \mathrm{C} \times \mathrm{D}$, four-way interaction term, $\mathrm{A} \times \mathrm{B} \times \mathrm{C} \times \mathrm{D}$ were statistically significant due to the $\mathrm{p}$-value lower than 0.05 . The insignificant terms were eliminated from the regression equation. The reduced regression equation for percentage removal of COD was written in terms of uncoded units after elimination of insignificant terms:

$$
\begin{aligned}
& Y_{2}=24.59+4.94 A-10.35 B-9.76 C-4.42 D-1.69(A \times B)-1.12(A \times C)-1.25(A \times D) \\
& +6.23(B \times C)+1.09(A \times B \times D)+0.36(B \times C \times D)
\end{aligned}
$$

The coefficient of determination for percentage removal of color and COD degradation were found to be 0.972 and 0.9874 . High $\mathrm{R}^{2}$ value denotes the stable of the proposed model. It is also noticed that the proposed model is unable to explain only about $2.8 \%$ and $1.26 \%$ of sample variation for percentage color removal and COD removal respectively. The interaction of independent variables on response variables namely color removal and COD removal is depicted in Fig. -2 .

The interaction among the variables on response variable was described by interaction plot (Fig.-2). pH is a statistically significant variable for the removal of color as well removal of COD since p-value lower than 0.05 as indicated in ANOVA table. The change in $\mathrm{pH}$ from 3 to 8 increases the percentage color removal and COD removal by about $20 \%$. Therefore, High $\mathrm{pH}$ range enhances adsorption of industrial dye on acid-treated sugarcane bagasse. In contrast, Ponnusami et al., $2007^{5}$ and Gong et al., $2005^{17}$ reported maximum color removal efficiency at low $\mathrm{pH}$. It is also found that color removal rate as well as COD removal rate increased by about $10 \%$ with an increase in adsorbent dosage from 3 to $8 \mathrm{~g} / \mathrm{dm}^{3}$. 
Similarly, increase in agitation speed increases the removal of color as well as COD. It might be so, because the increase in agitation speed increases the mass transfer coefficient as well as internal diffusivity due to a reduction in boundary layer thickness ${ }^{18}$. However, the increase in dilution factor decreases the color as well as COD removal rate. Similarly, Cueva-Orjuela et. al., $2017^{19}$ obtained maximum percentage removal of color with statistically significant variables namely dosage and dye concentration.

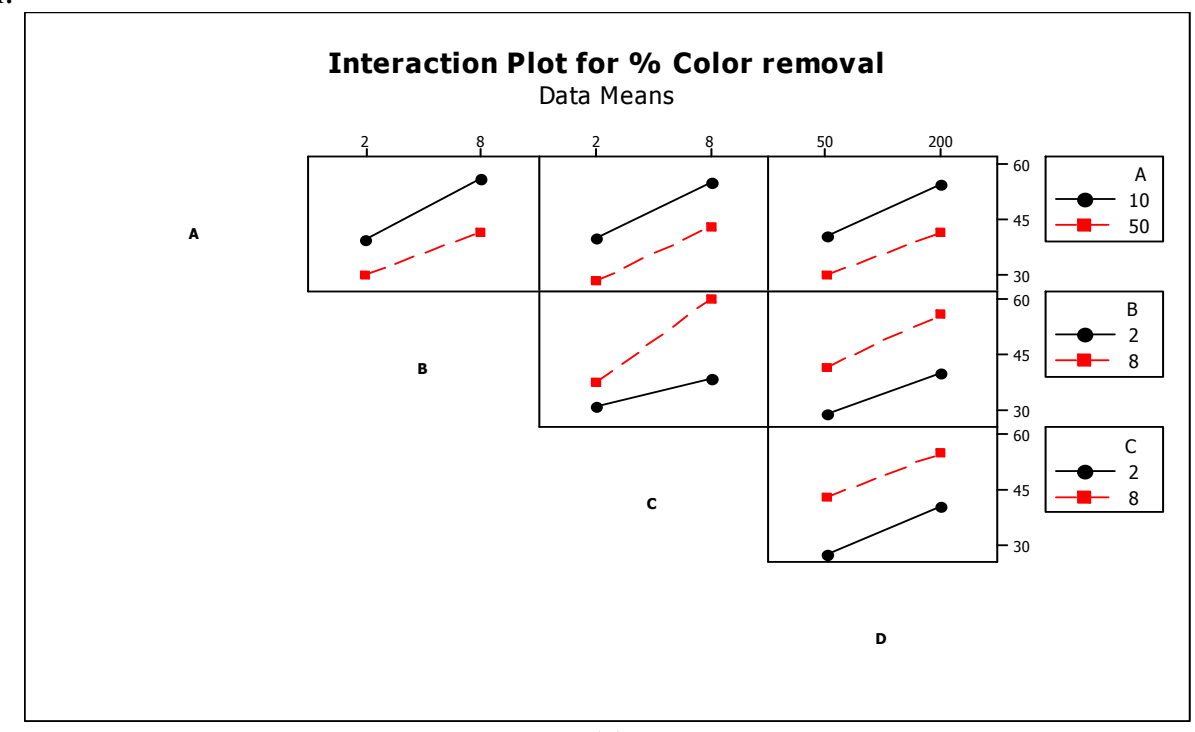

(a)

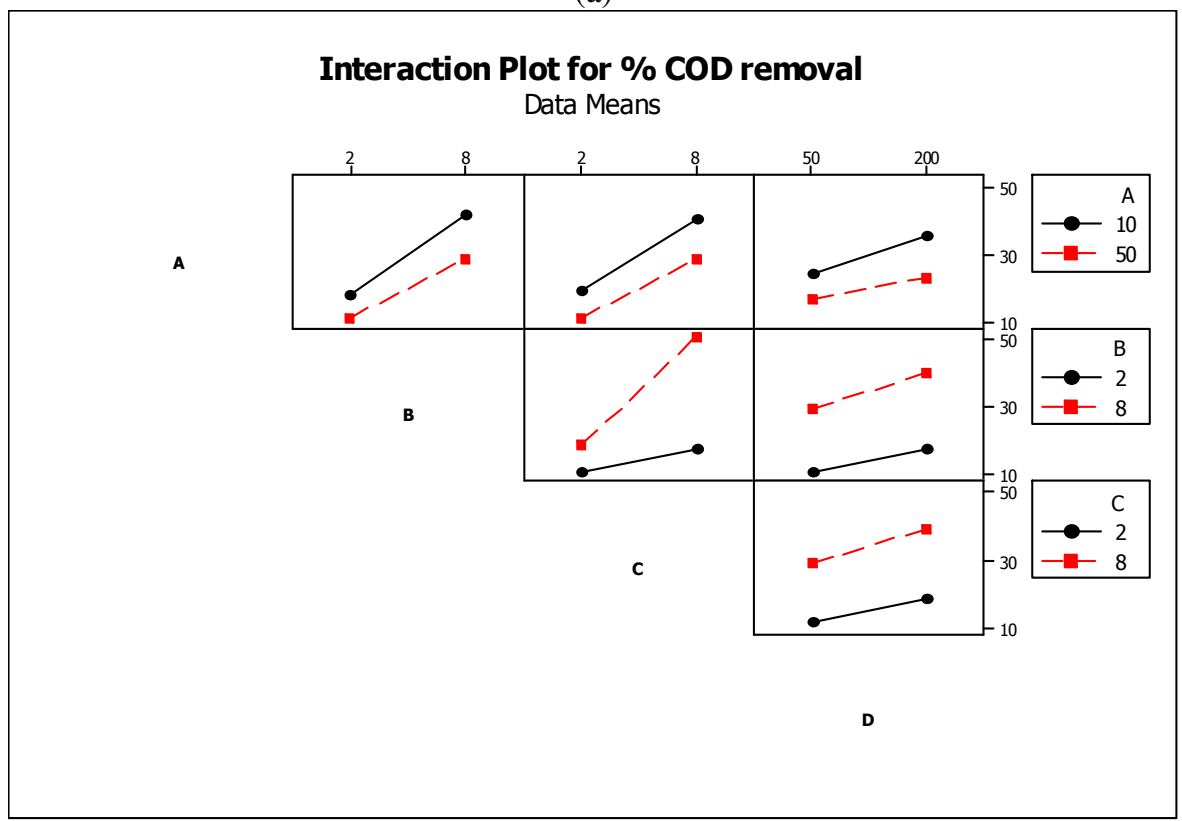

(b)

Fig.-2: Interaction plot (a) colour removal (b) COD removal

Vigneshpriya and Shanthi, $2016^{20}$ explained the influence of different factors namely $\mathrm{pH}$, adsorbent dosage and temperature on percentage color removal from real-time textile effluent by biosorption technique. Aseel et.al., $2017^{21}$ reported the adsorption of cationic dye (BR46) on to sugarcane bagasse by statistical design of experiments.

The residues in the regression model were analyzed by a normal distribution. In the residual plot, standard residues and response variables were placed in horizontal and vertical axis respectively. The linear regression could be preferred if the residues are uniformly distributed in the horizontal axis. Fig.-3, 
explains the normal probability chart for residual values for percentage color removal and COD removal. It is observed that all the experimental points are well fitted with predicted values signifying normal distribution. All the experimental points are reasonably distributed between +2 and -2 in the residual plot of percentage color removal and COD removal and residual (Fig.-3). Also, all the standard residuals placed near to straight line indicates the normal error distribution. And also, the relationship between percentage removal of color and COD and residuals were explained by predicted versus residual plot.

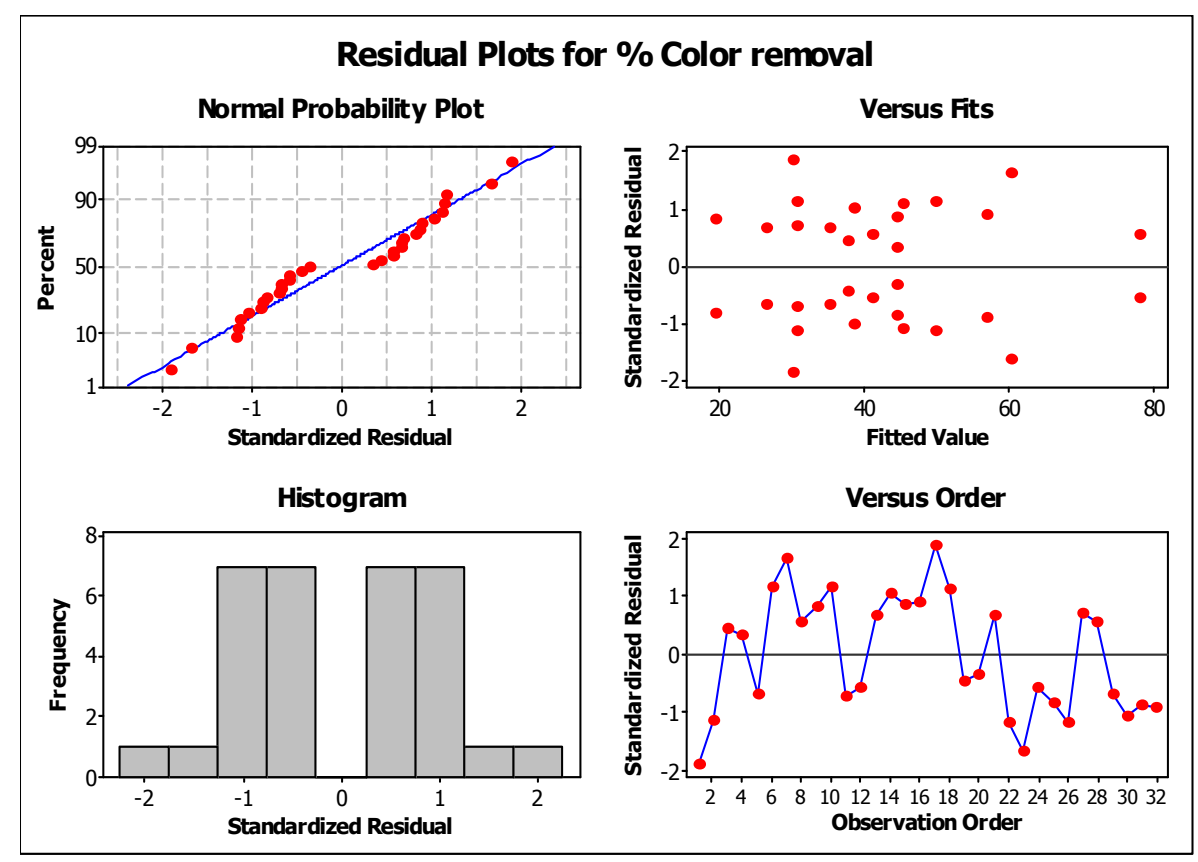

(a)

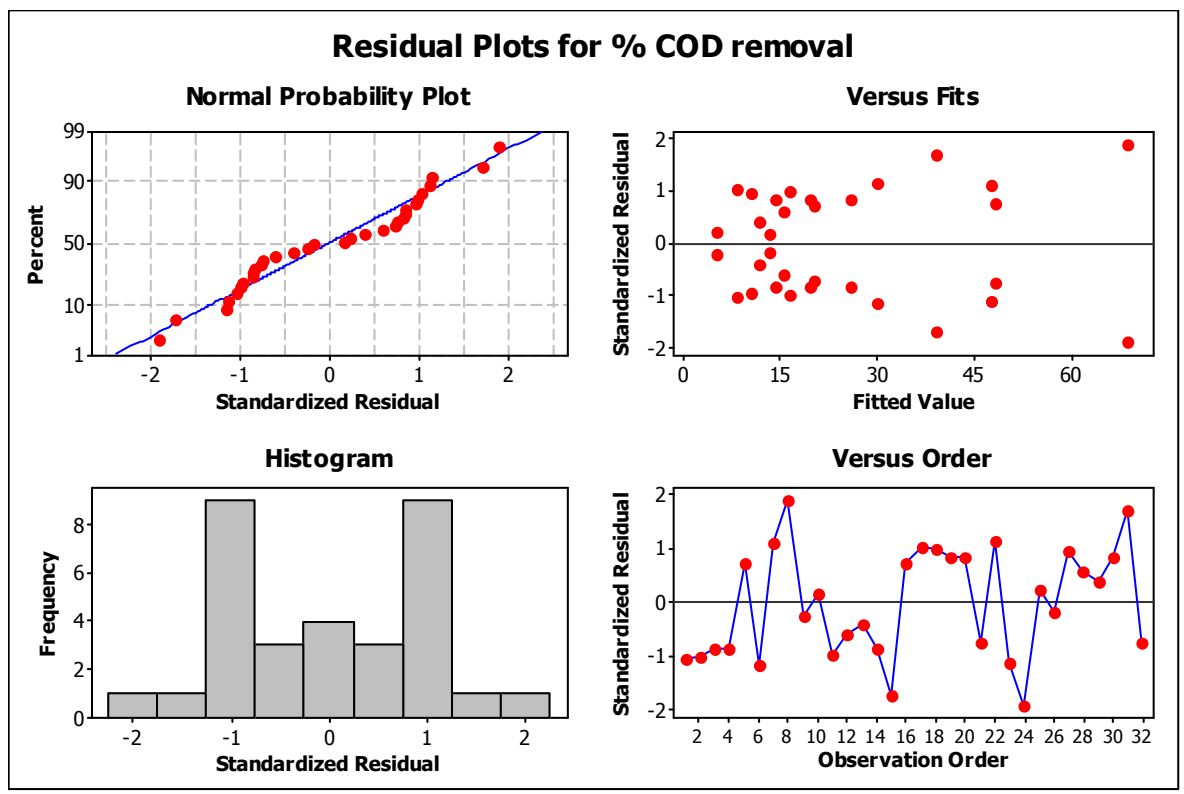

(b)

Fig.-3: Residual plots (a) colour removal; (b) COD removal

\section{CONCLUSION}

(i) In this study, the factorial design of experiments was employed for the treatment of real-time industrial effluent using acid treated sugarcane bagasse as an adsorbent. 
(ii) The Main effect and interaction among the process variables namely dilution percentage, adsorbent dosage, initial $\mathrm{pH}$, agitation speed on response variables, \% color removal and \% COD removal were examined.

(iii) The following process variables were obtained for maximum removal of colour as well as COD: percentage dilution $=10 \%$; Adsorbent dosage $=8 \mathrm{mg} / \mathrm{dm}^{3}$; Initial $\mathrm{pH}=8$; Agitation speed $=200 \mathrm{rpm}$.

\section{REFERENCES}

1. Y. Fu, T. Viraraghavan, Bioresearch Technology, 79, 251(2001)

2. A. Jumasiah, T. G. Chuah, J. Gimbon, T. S. Y. Choong, I. Azni, Desalination, 186(1-3), 57(2005), DOI: $10.1016 / 2005.05 .015$.

3. P. Saha and S. Datta, Desalination and Water Treatment, 12, 219 (2009), DOI: 10.7324/RJC.2017.1041865

4. R. Gong, Y. Jin, Y. Chen and J. Hu. Sun, Dyes Pigments, 73, 332 (2006), DOI: 10.1016/2006.01.037

5. V. Ponnusami, R. Madhuram, V. Krithika and S. N. Srivastava, Journal of Hazardous Materials, 142, 397(2007).

6. M. S. El-Geundi, Water Research, 25, 271(1991), DOI: 10.1016/0043-1354(91)90006

7. V. J .P. Poots, G. McKay, J. J. Healy, I Peat Water Res., 10, 1061(1976), DOI: 10.1016/00431354(76)90036

8. G. S. Gupta, G. Prasad, V. N. Singh, Water Res, 24. 45(1990), DOI:10.1016/0043-1354(90)90063

9. V. Vadivelan, K. V. Kumar, J. Coll. Interface Sci, 286, 90(2005), DOI: 10.1016/j.jcis.2005.01.007

10. Y. Bulut, H. Aydın, Desalination, 194, 259(2006), DOI:10.1016/j.desal.2005.10.032.

11. V. S. Mane, I. D. Mall, V. C .Srivastava, Dyes and Pigments, 73(3), 269(2007), DOI: 10.1016/j.dyepig.2005.03.013

12. V. Ponnusami, S. Vikram, S. N. Srivatsava, Journal of Hazardous Materials, 152, 276(2008), DOI: 10.1016/j.jhazmat.2007.06.107.

13. E. Bazrafshan, M. Ahmadabadi, A. H. Mahvi, Fresenius Environmental Bulletin, 22(2a), 584(2013a), DOI: $10.2166 /$ wst.2017.479

14. V. Gunasekar, V. Ponnusami, Journal of Chemistry, Article ID 259819, 5 pages (2013).

15. V. Jayanthi, N. Sudarmanigayathri, International Journal of Pharma \& Biosciences, 6(2), 584(2015), DOI: 10.22376/ijpbs.

16. R. Krishna Prasad, S. N. Srivastava, Chemical Engineering Journal, 146 (1), 22-29 (2009), DOI: 10.1016/j.cej.2008.05.008

17. R. Gong, Y. Sun, J. Chen, H. Liu, C. Yang, Dyes Pigments, 67, 175(2005).

18. V. Ponnusami, K. S. Rajan, S. N. Srivastava, Chem. Eng. J, 163, 236(2010).

19. J. C. Cueva-Orjuela, A. Hormaza-Anaguano, A. Merino-Restrepo, DYNA, 84(203), 291(2017), DOI:10.15446/dyna.v84n203.61723.

20. D. Vigneshpriya, E. Shanthi, International Journal of Current Research, 8(5), 31324(2016).

21. Aseel M. Aljeboree, Abbas N. Alshirifi, Ayad F. Alkaim, Arabian Journal of Chemistry 10, S3381 (2017).

[RJC-2086/2018] 